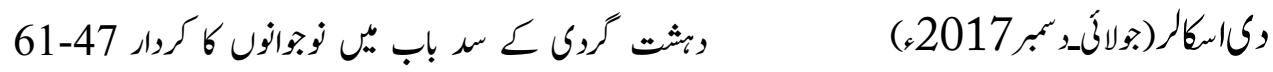

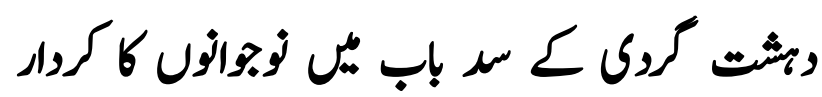

$$
\begin{aligned}
& \text { (تحلمات نبوككروشثي. }
\end{aligned}
$$

\title{
URDU-THE ROLE OF YOUTH TO ELIMINATE THE TERRORISM (IN THE LIGHT OF PROPHET (S.A.W) ŞEERÂH)
}

\author{
Dr. Ahmad Hassan*, Dr. Noor Hayat Khan** \\ The Scholar Islamic Academic Research Journal || Web: www.siarj.com \| \\ P. ISSN: 2413-7480 || Vol. 3, No. 2 || June-December 2017 || P. 47-61 \\ DOI: 10.29370/siarj/issue5ar3 \\ URL: https://doi.org/10.29370/siarj/issue5ar3 \\ License: Copyright c 2017 NC-SA 4.0
}

\begin{abstract}
:
Islam is the Religion of nature and prohibits all such deeds that explicitly or implicitly promote violence. Our Holy prophet has repudiated every such route of which could potentially disrupt the environment Peace and prosperity. The Holy prophet preached and practiced the best in every aspect of life. So, Islam and last prophet (S.A.W) life serves as a guideline, not only for Muslims but for people all over the world as to make life easier for everyone and show them the way to an ideal life. Islam as a universal Religion, that seeks to bring people together irrespective of their religious, class, creed or gender difference. It seeks to in still peace in every individual who looks for it and therefore bring them in with each other. And we must support our adults as to provide them peace education, and we must engage him as a worker on community development projects. The main results included increased adult awareness of the situation and needs of youth, improved youth-adult relations, reduced perceptions of youth as troublemakers, reduced fighting between youth, increased community planning, and increased perceptions that youth make a positive contribution to the community. The results suggest that a dual focus on youth and community

\footnotetext{
* Ex Lecturer Islamic Center Copenhagen Denmark, Email:Dr.hassanktk786@gmail.com ** Associate Professor, Department of Islamic Studies, NUML H-9 Islamabad, Email: noor.hayatdr@gmai.com
} 


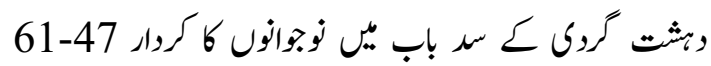

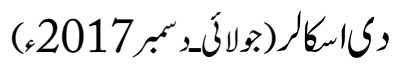

development contributes to peacebuilding and the disruption of cycles of violence. Extremism is unacceptable term in Religion and one of the most reliable tactics of the satin that could easily entangles the honest pions people in their prey and digress them from their Religion. Our beloved country is a victim of extremist and terrorist activities. Extremism and terrorism is Cancer for my society, sinister circumstances of our country demand the role of educated youth to come forward and utilize their intrust energy and potential in the lights of rules and principles of our peace prophet to kick this plague in the bud from the land of the pure.

KEYWORDS: Explicitly, Violence, Community, Circumstances,

Contributes, Principles, Nations, Plague

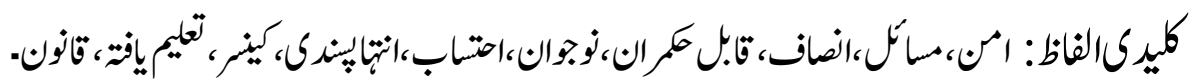

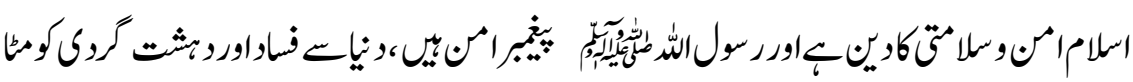

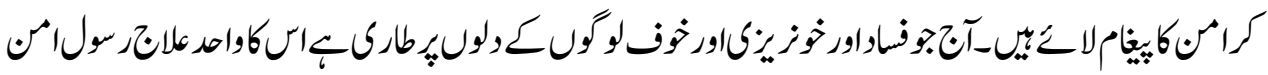

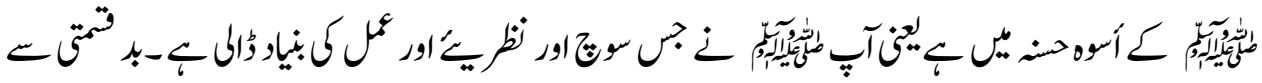

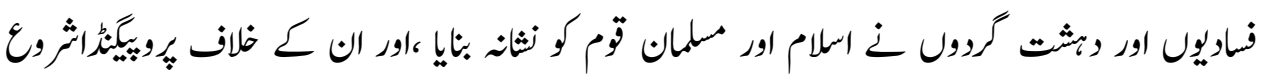

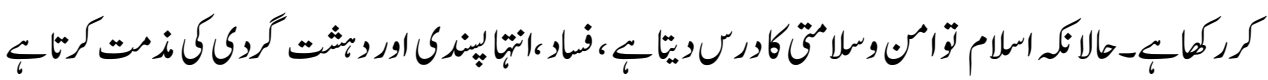

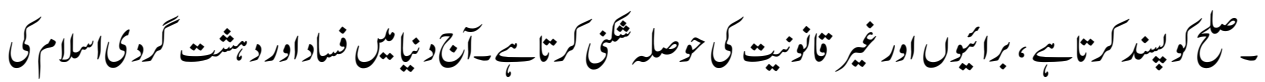

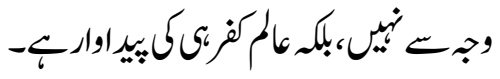

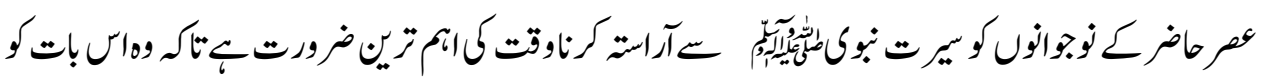

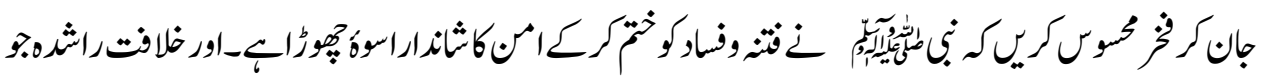

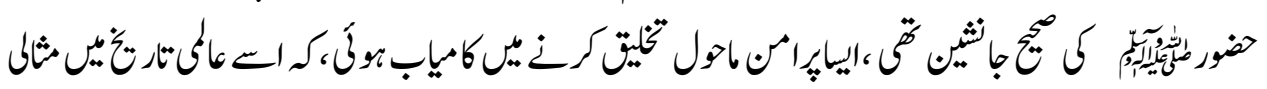
حيثيت كُوكئ-

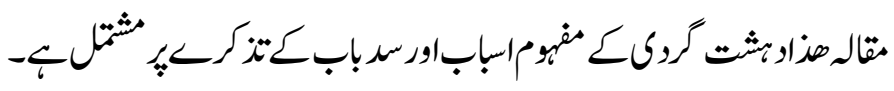
,

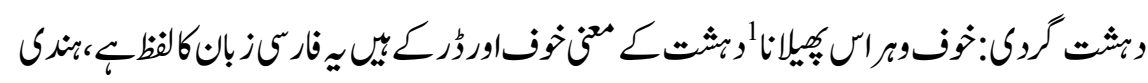




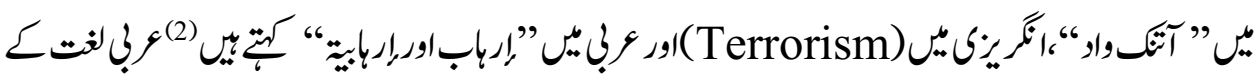

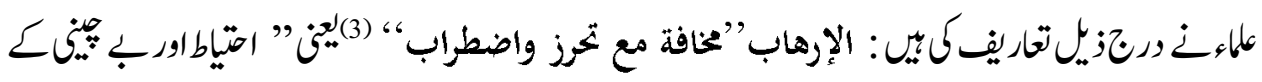

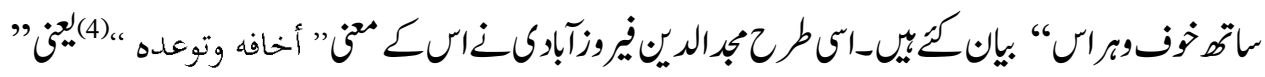

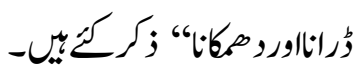

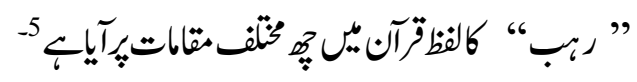

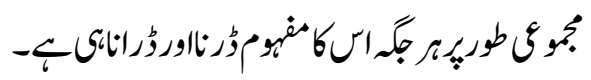

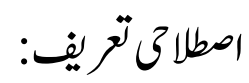

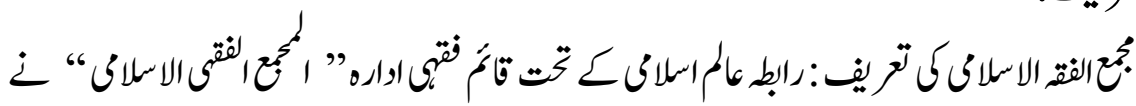

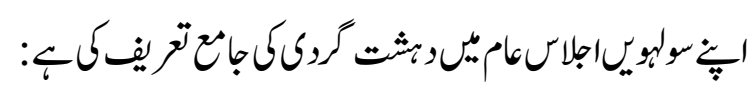

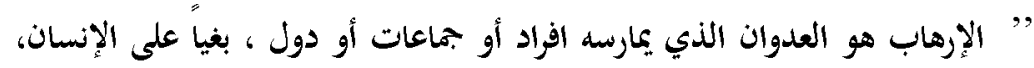
دينه و دمه و عقله وماله و عرضه، يشمل صنوف التخويف والأذي والتهديد والقتل التهل

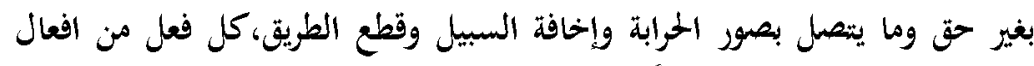

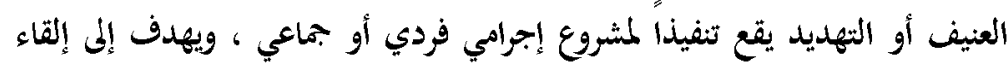

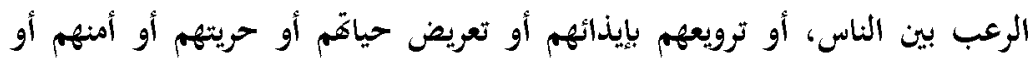

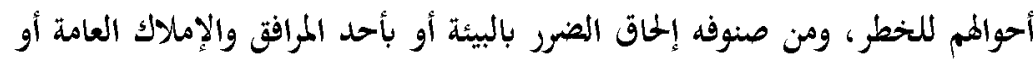

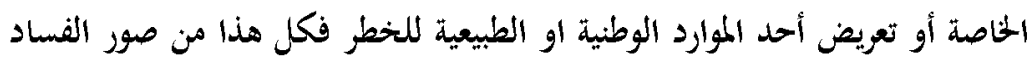

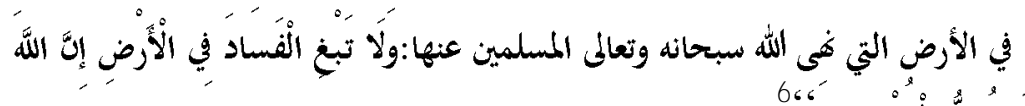

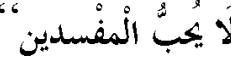

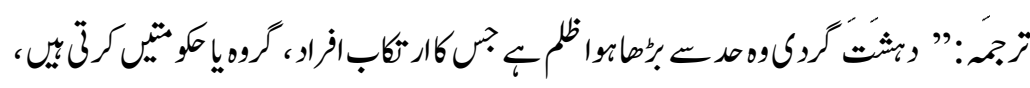

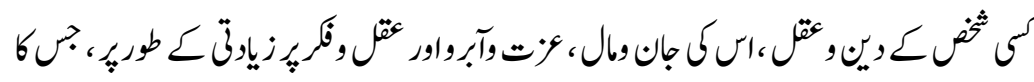

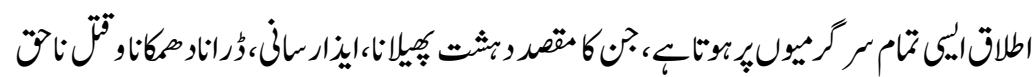

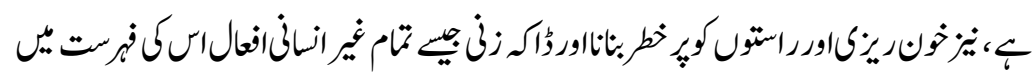

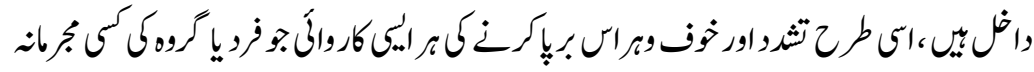

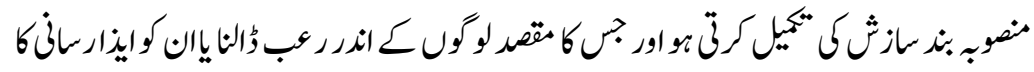

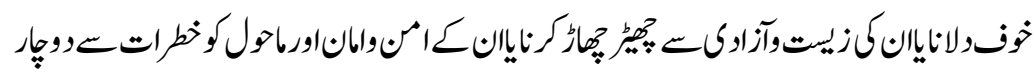




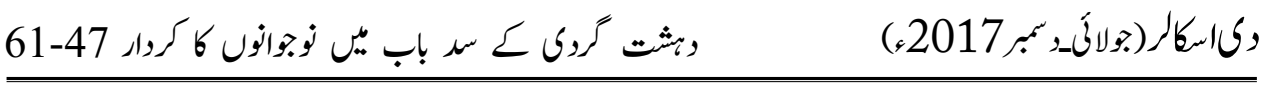

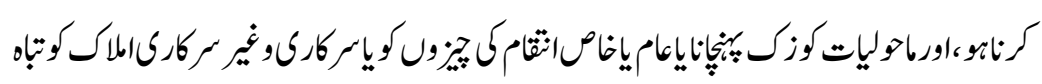

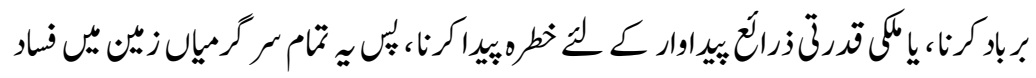

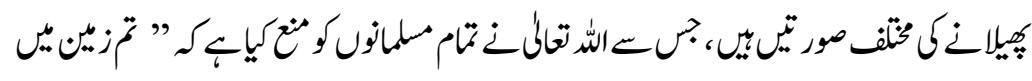

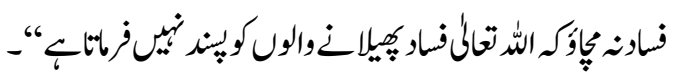

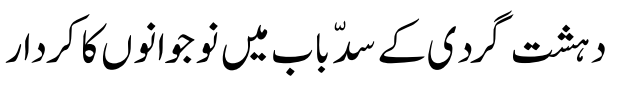

$$
\begin{aligned}
& \text { 每 } \\
& \text { ا- } \\
& \text { r }
\end{aligned}
$$

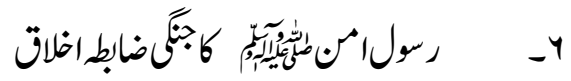

$$
\begin{aligned}
& \text { rاـ }
\end{aligned}
$$

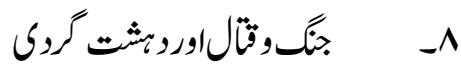

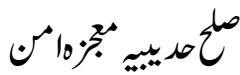

$$
\begin{aligned}
& \text { •إ- }
\end{aligned}
$$

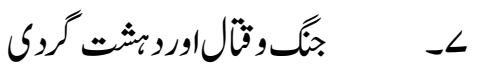

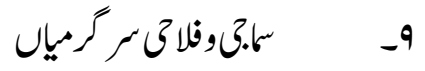

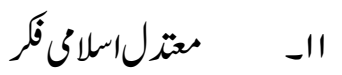

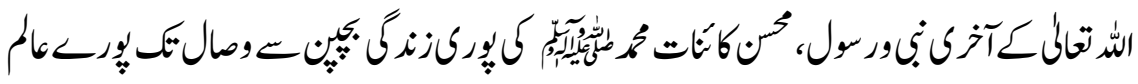

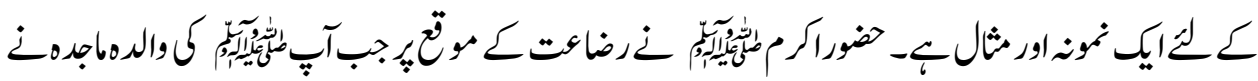

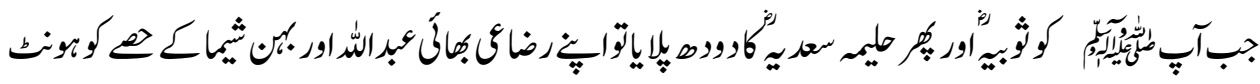

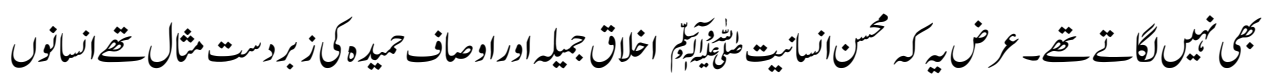

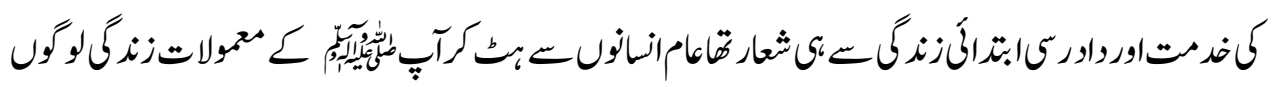

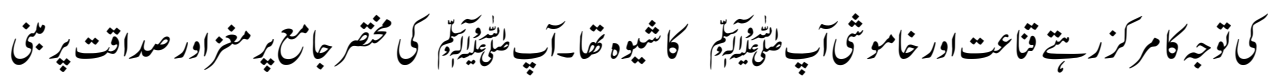

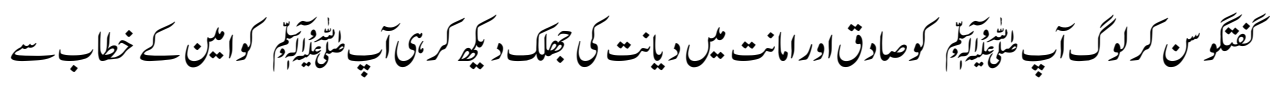

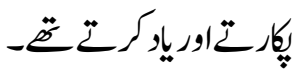

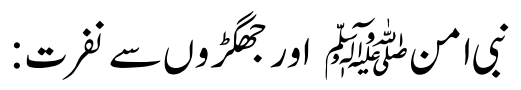

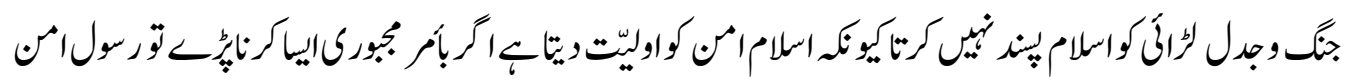

员

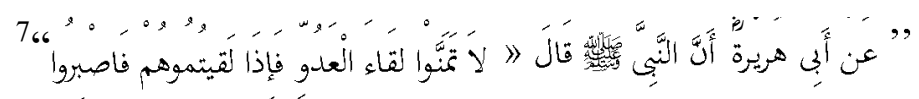

50 


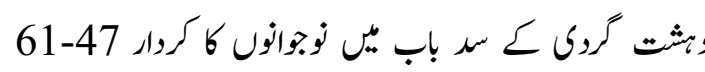

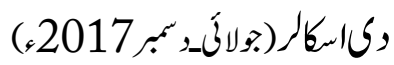

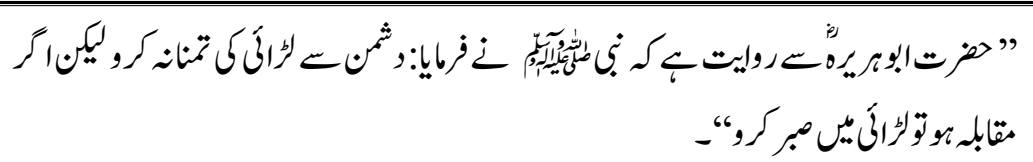

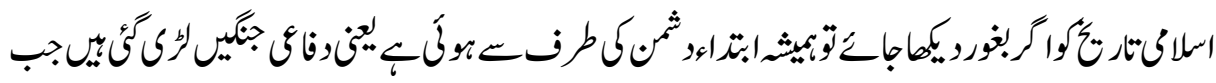

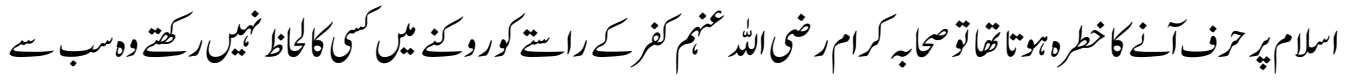

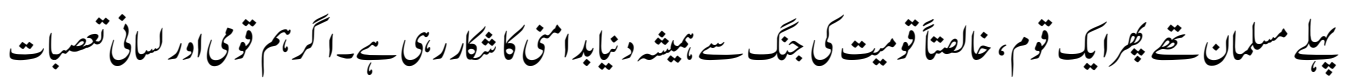

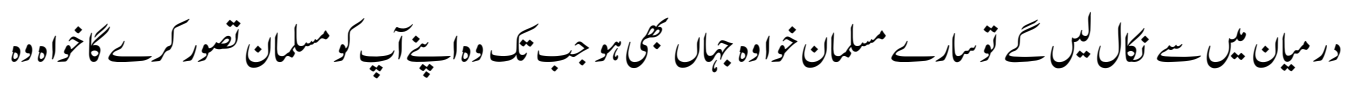

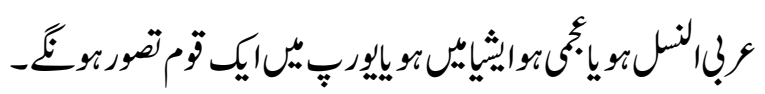

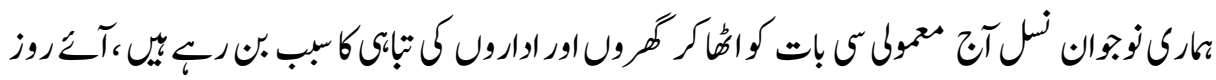

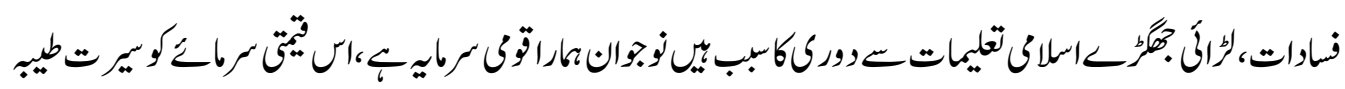

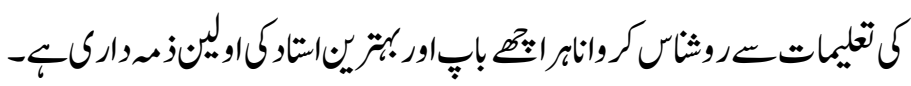

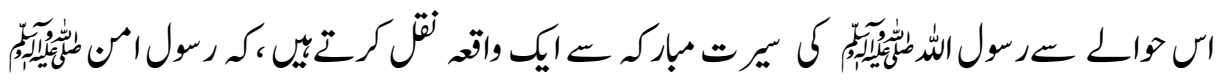

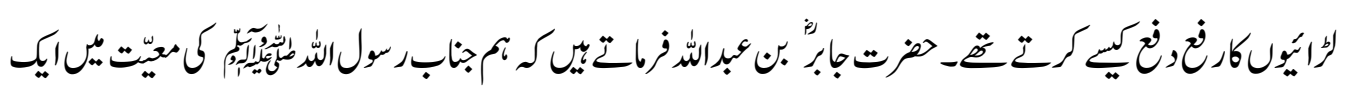
زثون

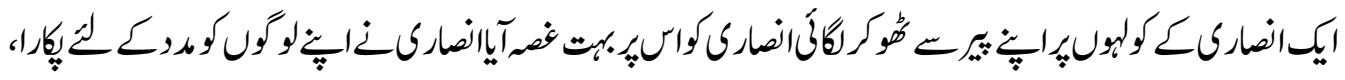

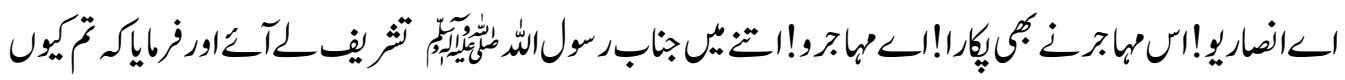

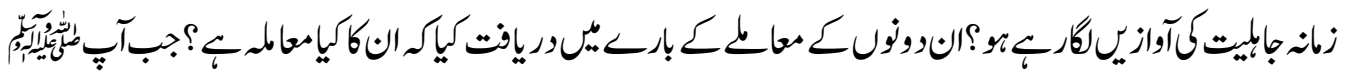

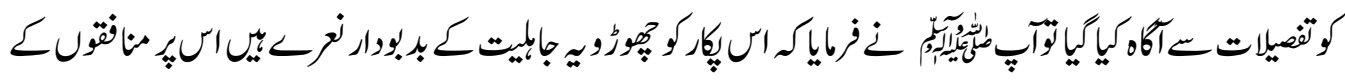

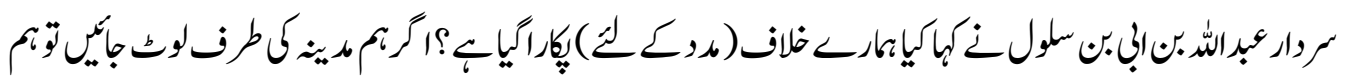

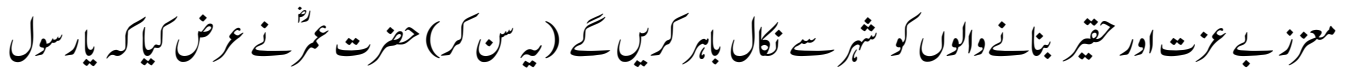

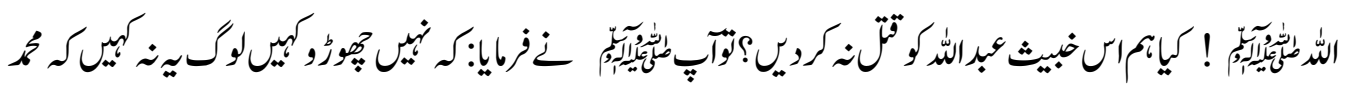

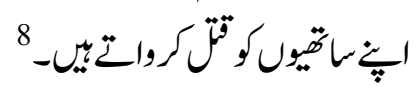

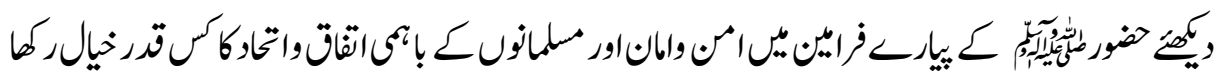

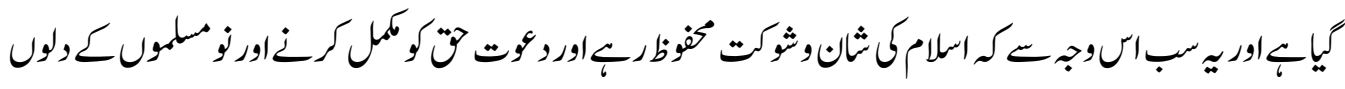

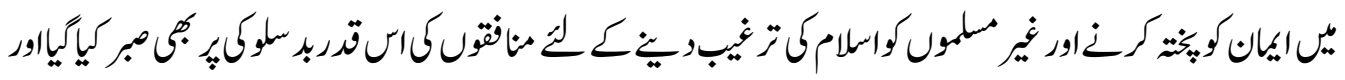




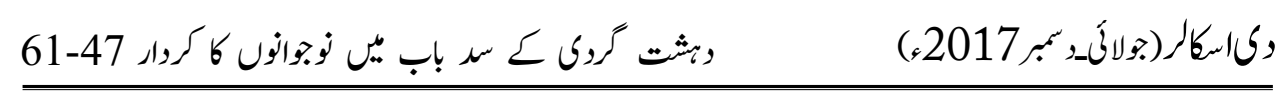

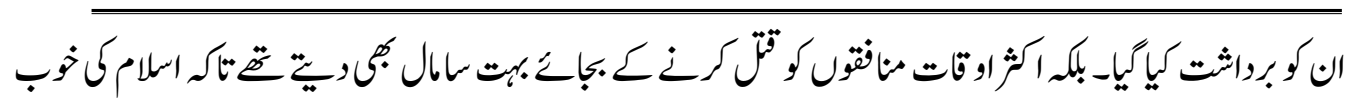

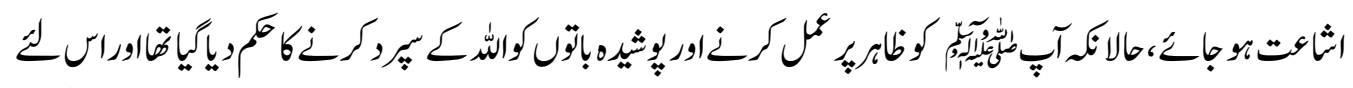

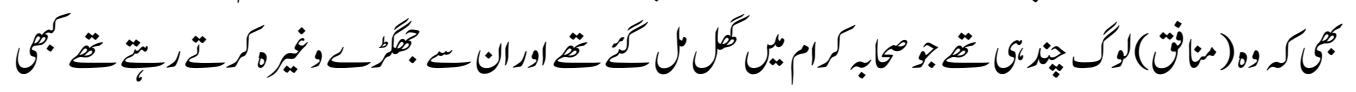

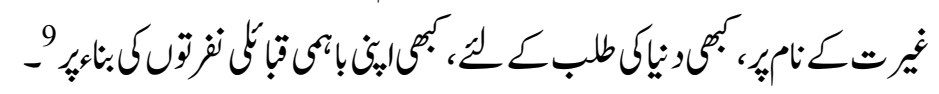

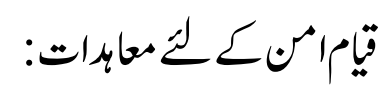
معابرام امثنف ملف الفضول

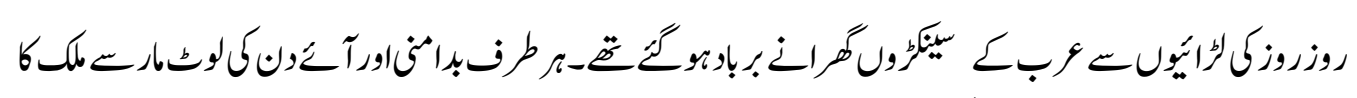

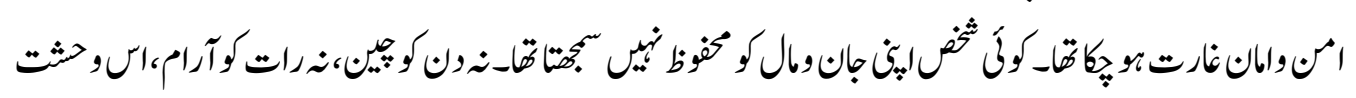

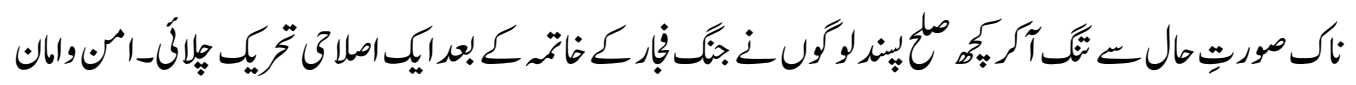

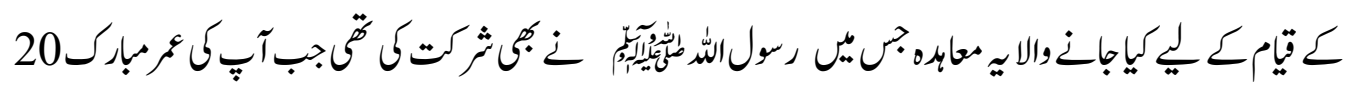
مالق

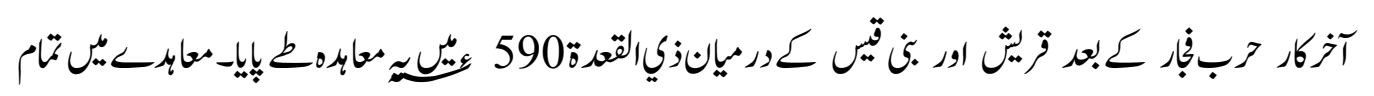

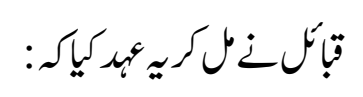
1

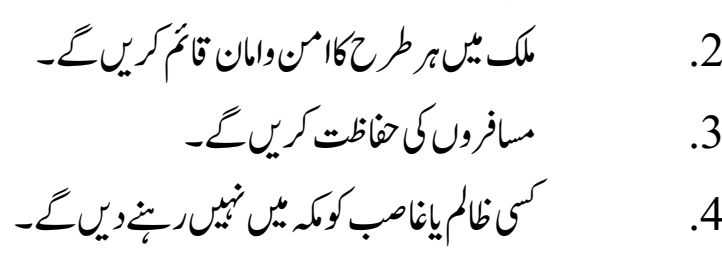

5.

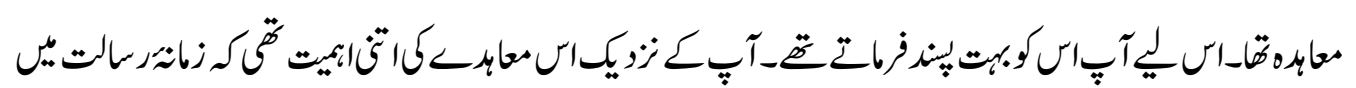

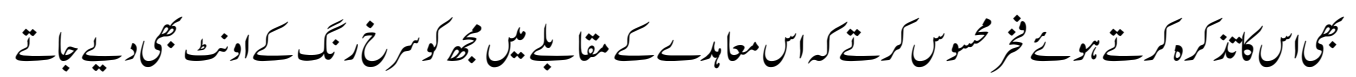

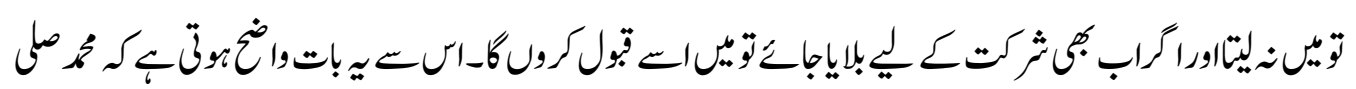

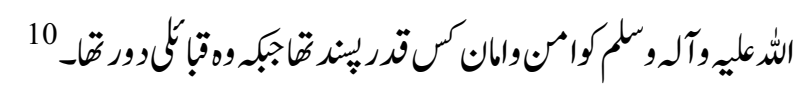

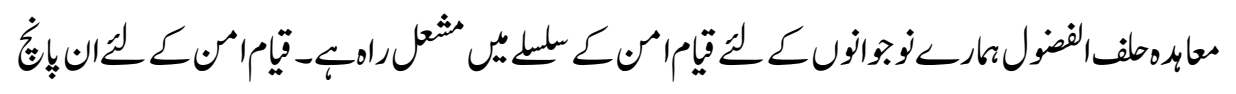




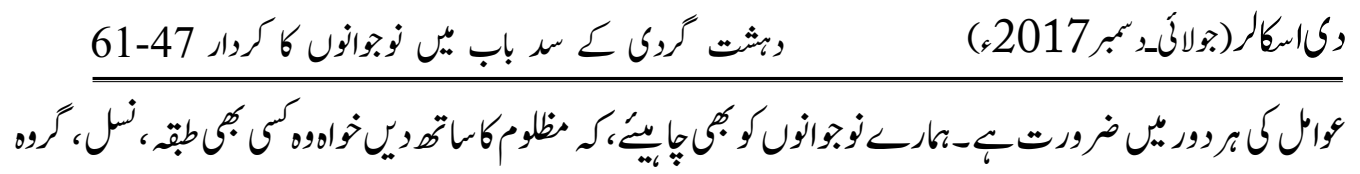

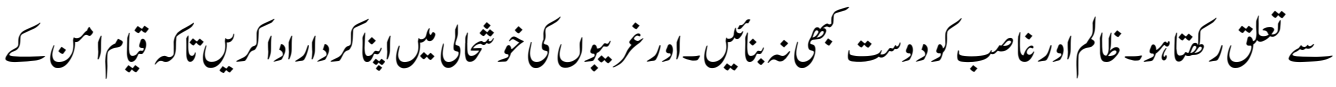

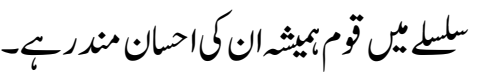

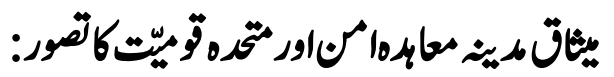

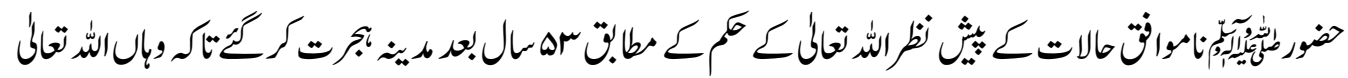

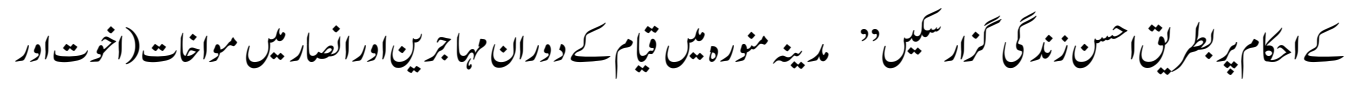

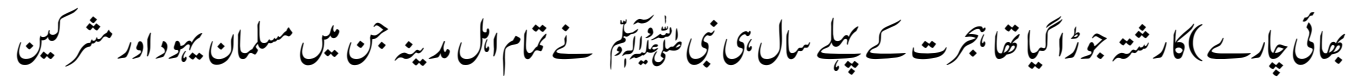

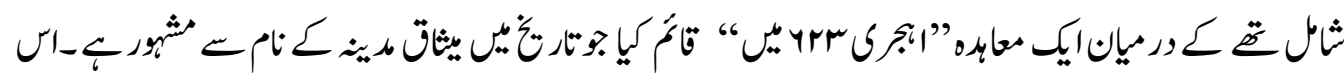

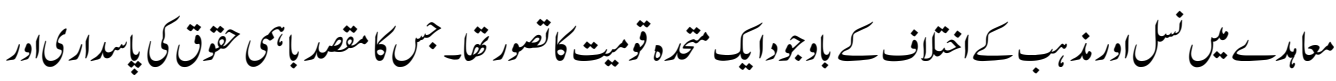

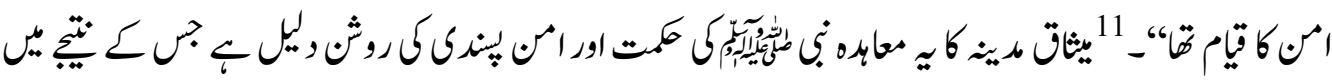

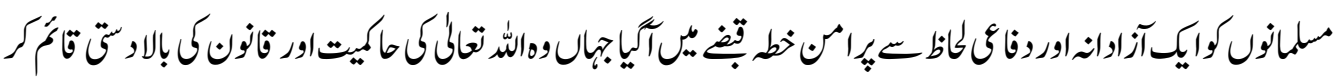

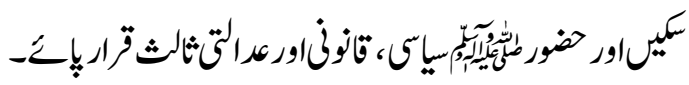

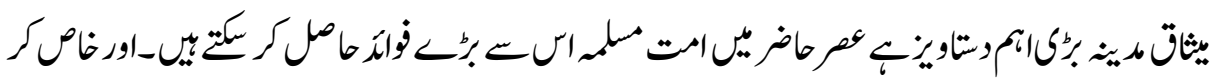

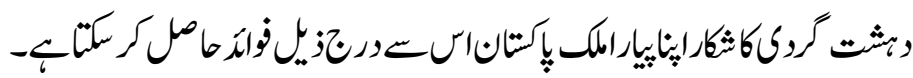

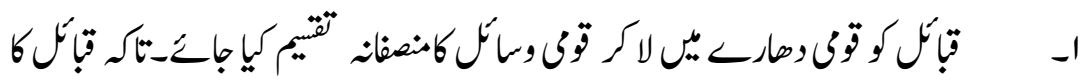

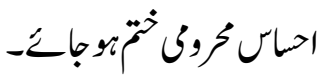

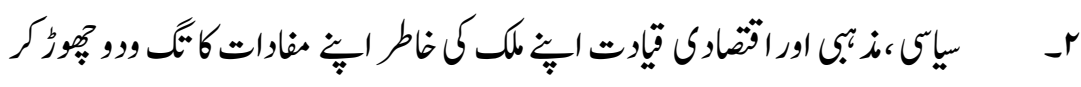

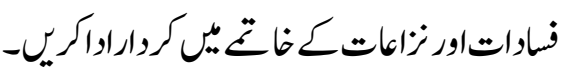

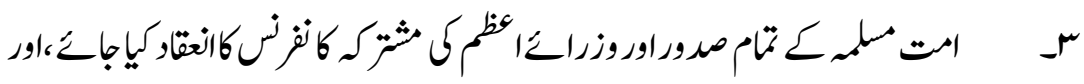

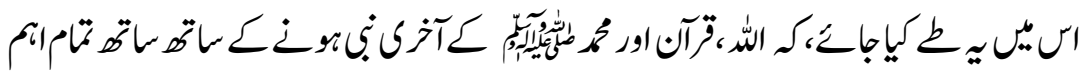

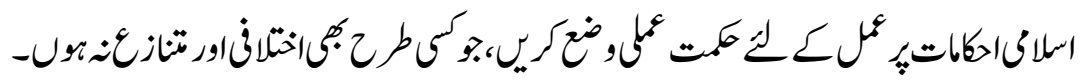

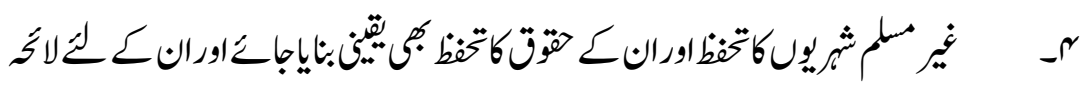

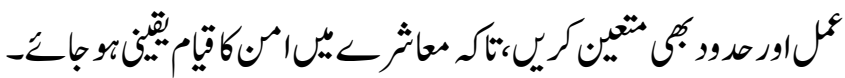
هـ 


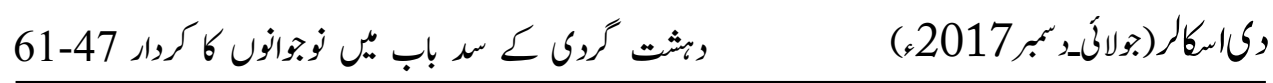

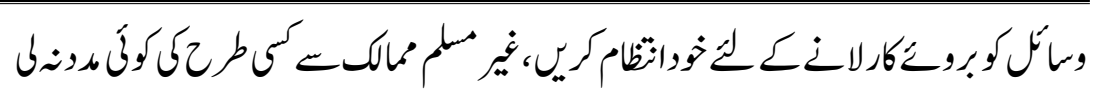

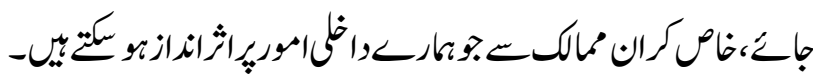

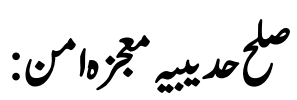

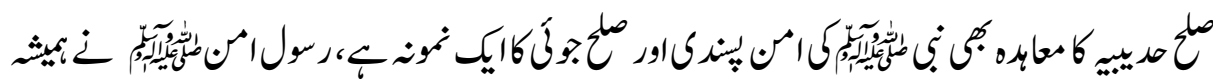

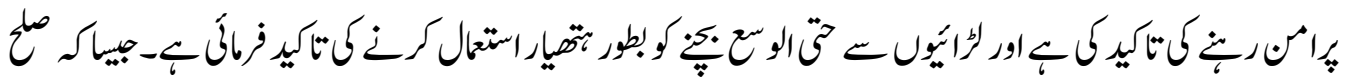

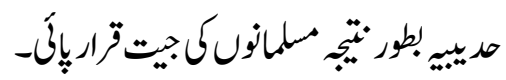

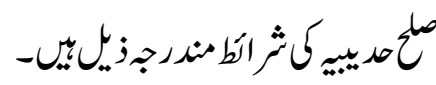

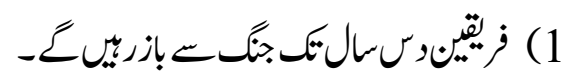

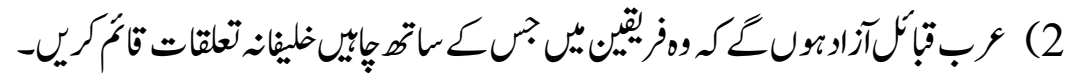
3

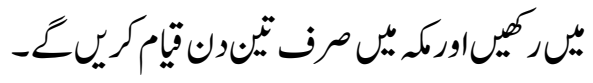

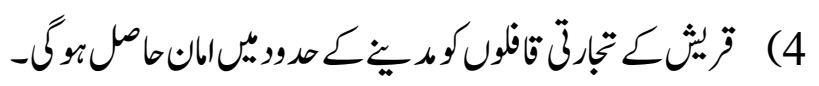

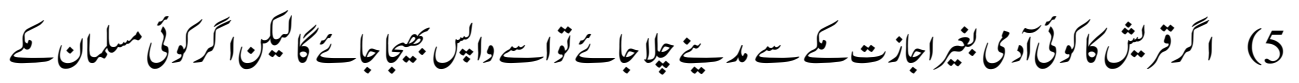

:

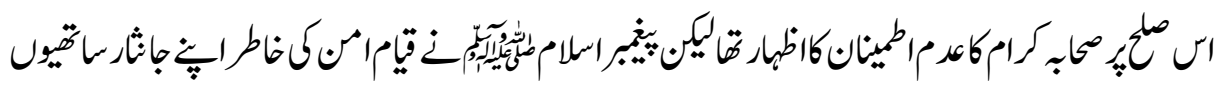

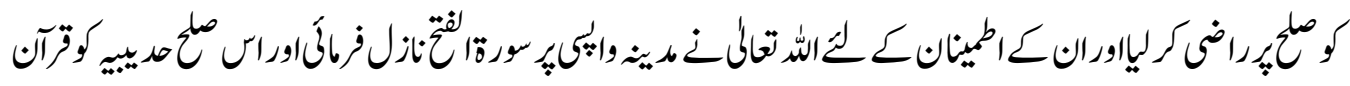

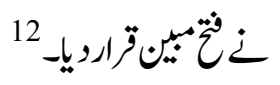

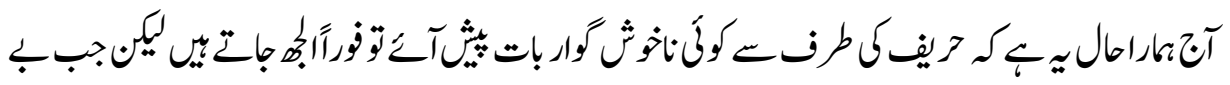

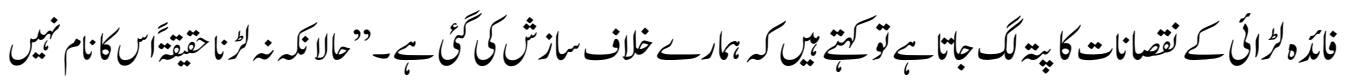

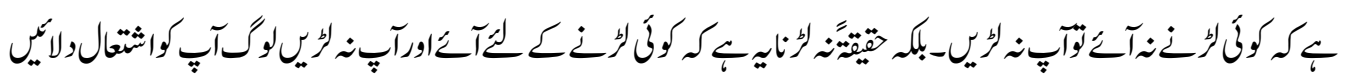

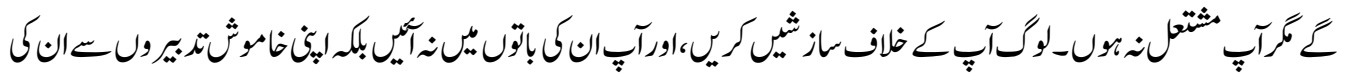

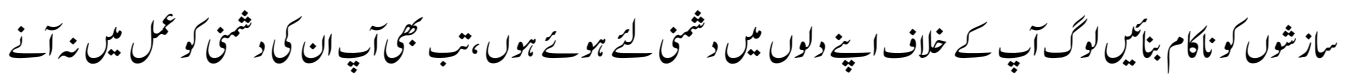

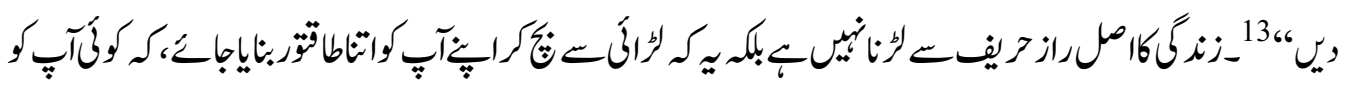

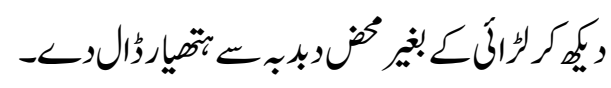




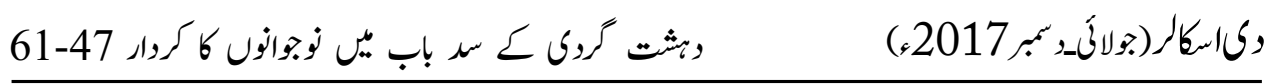

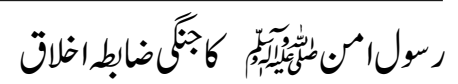

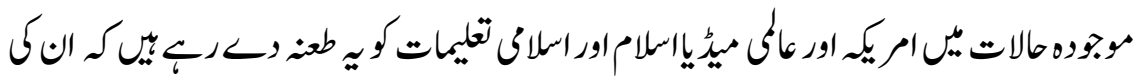

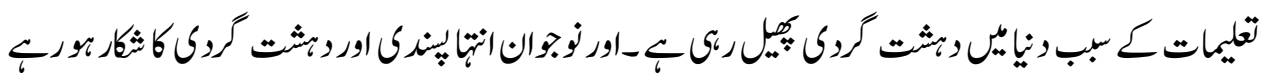

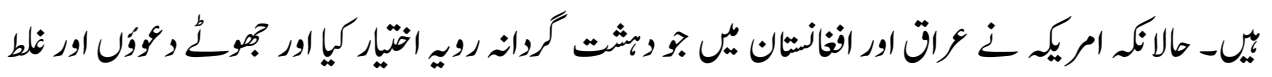

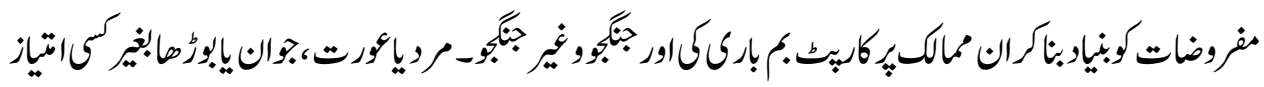

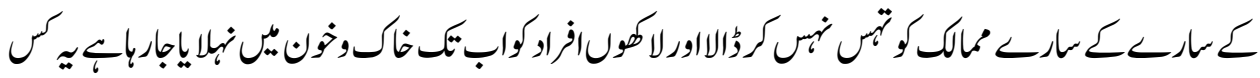

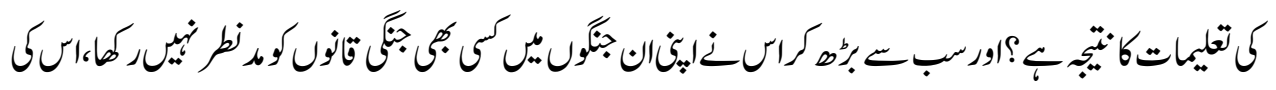

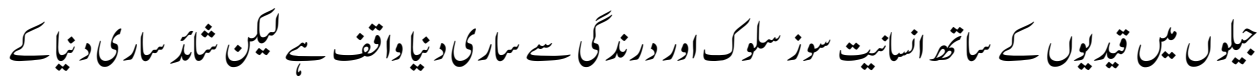

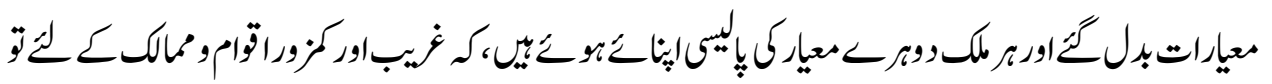

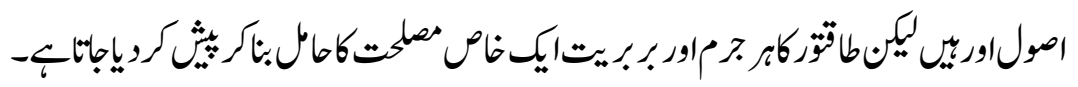

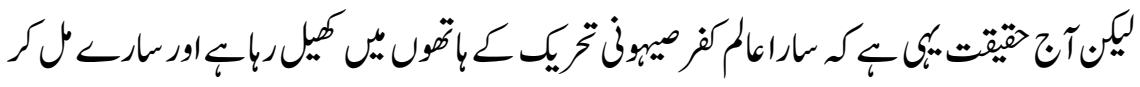

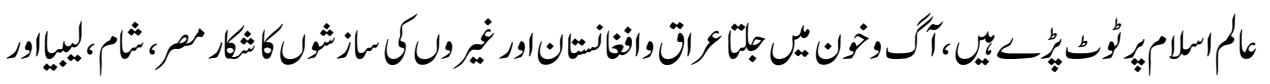

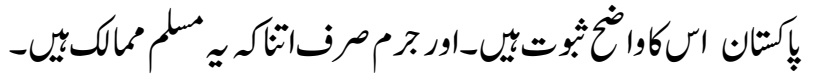

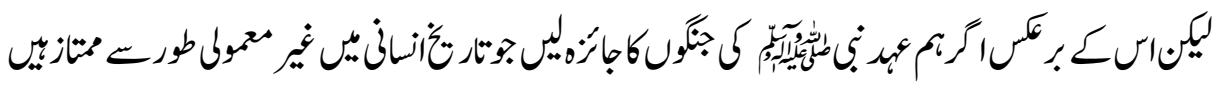

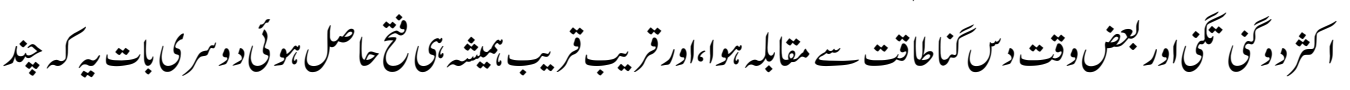

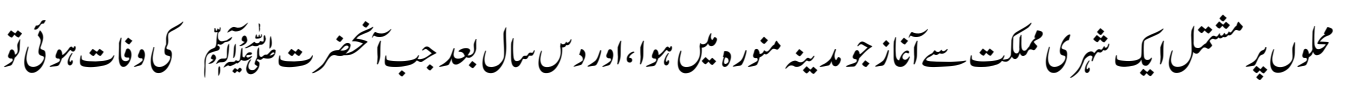

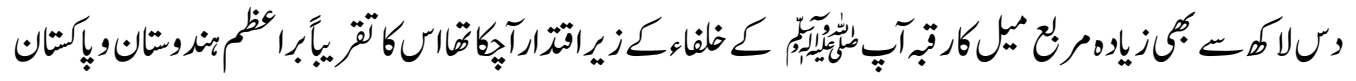

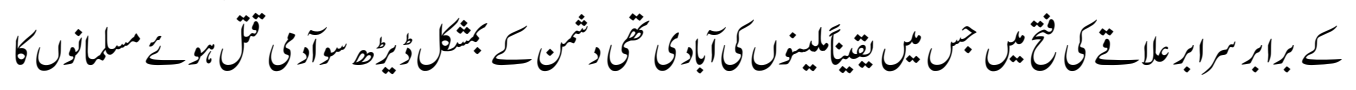

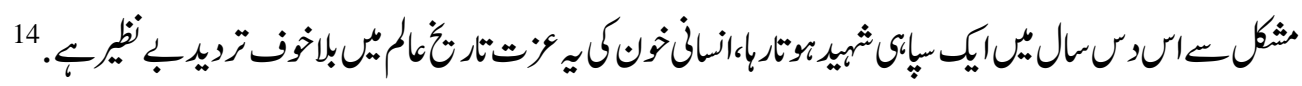

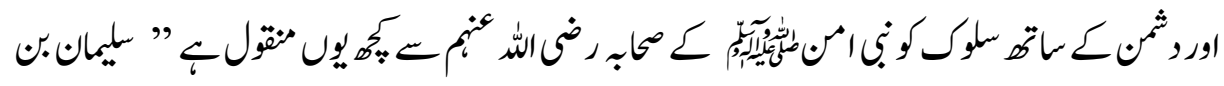

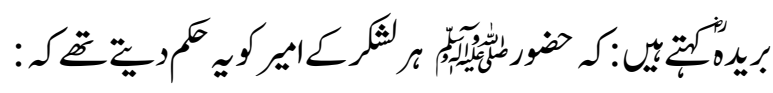

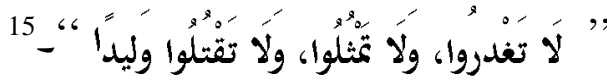

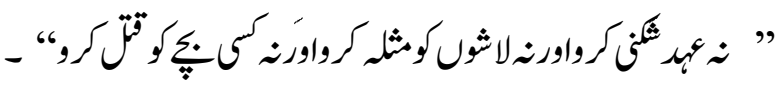

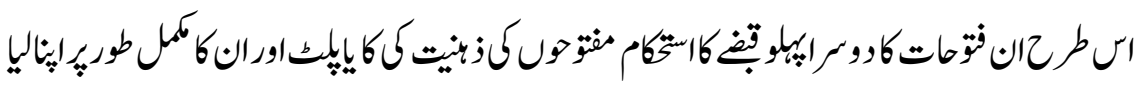

55 


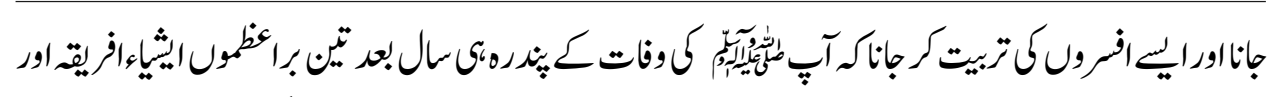

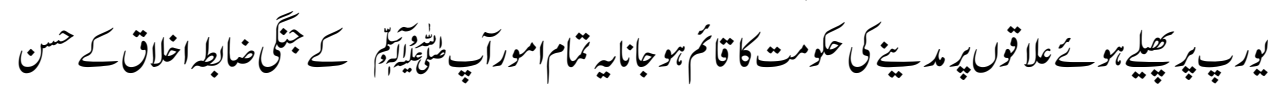

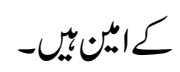

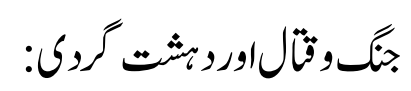

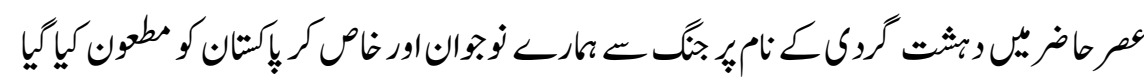

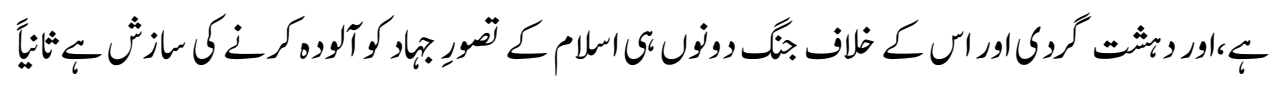

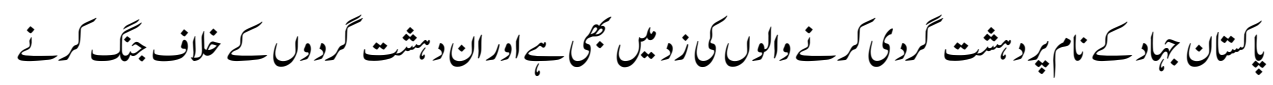

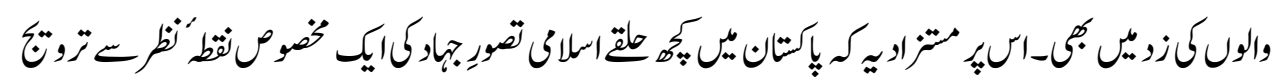

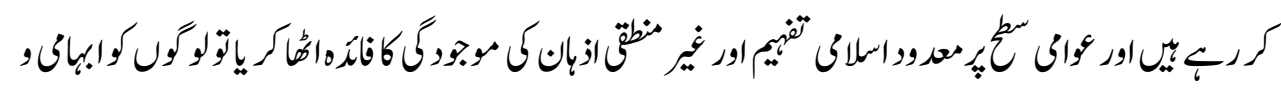

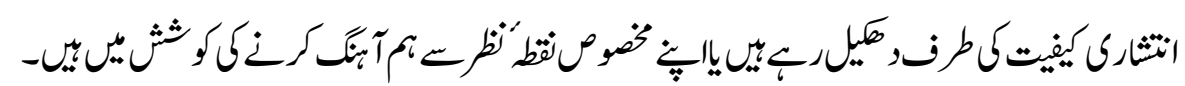

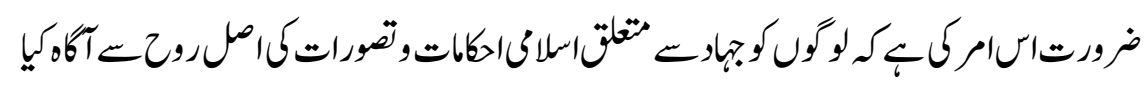

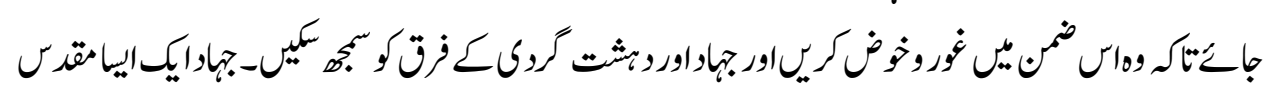

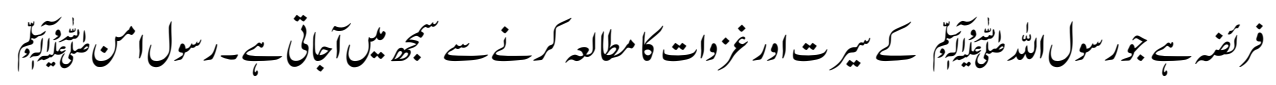

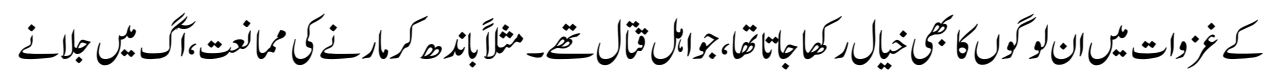

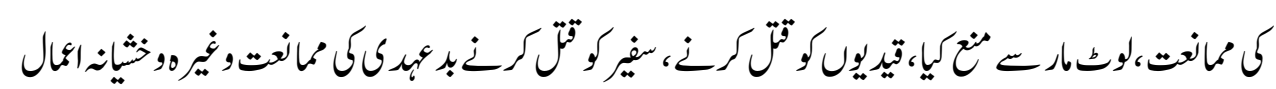

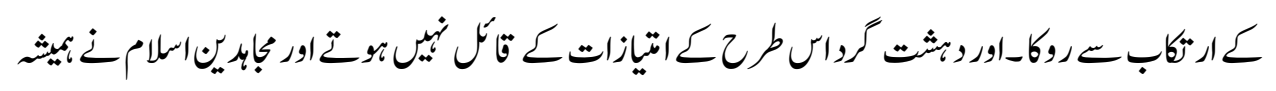

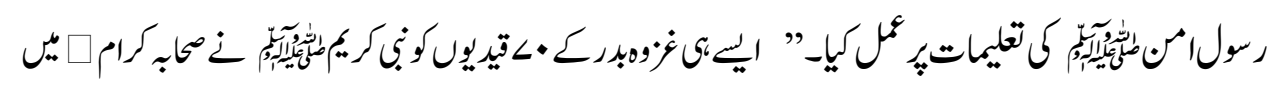

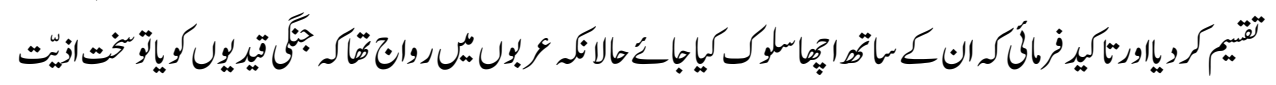

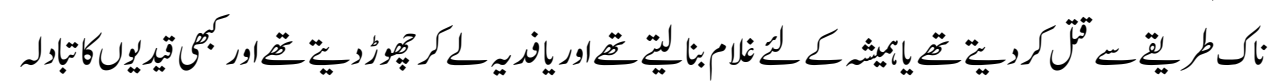

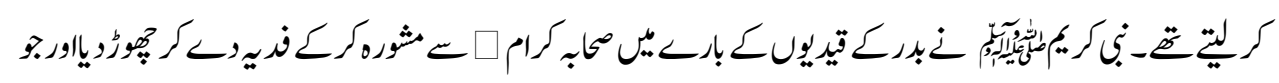

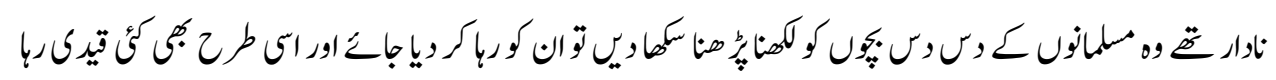

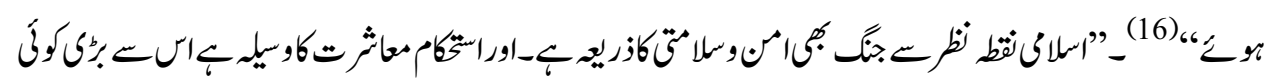

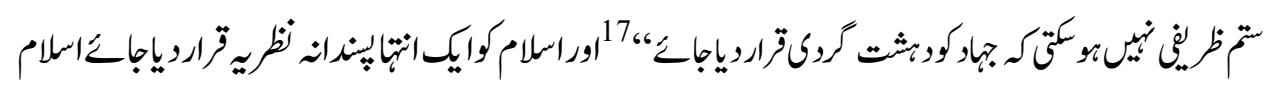

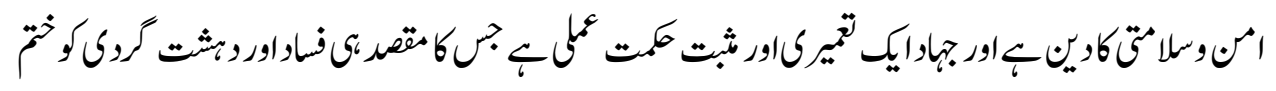




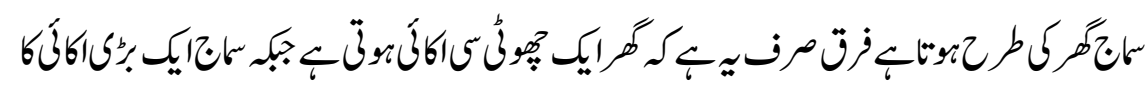

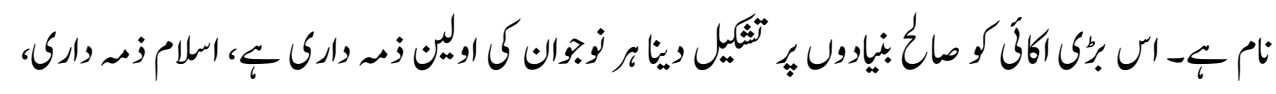

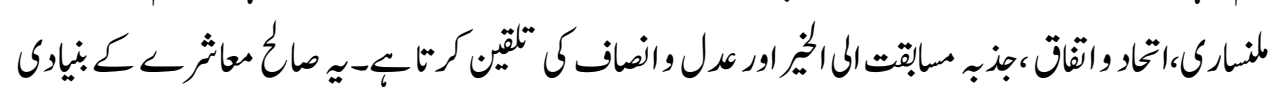

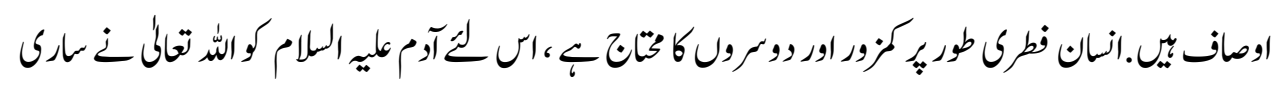

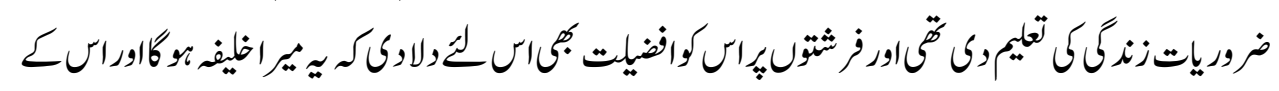

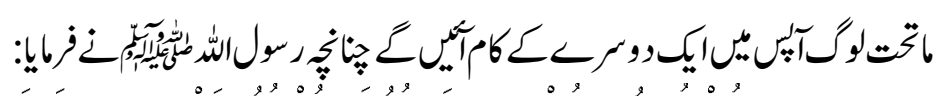

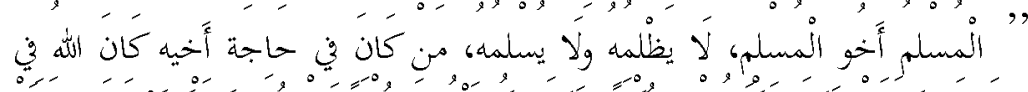

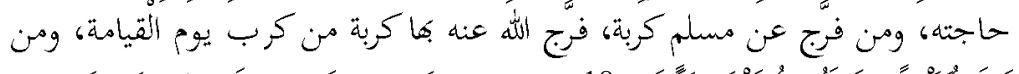

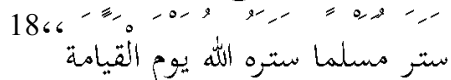

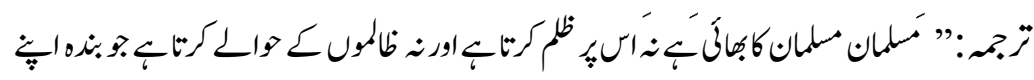

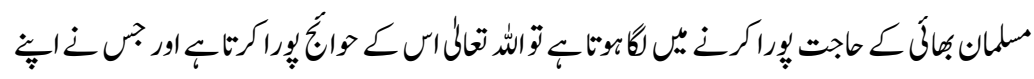

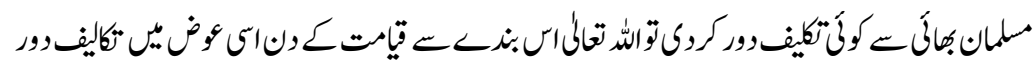

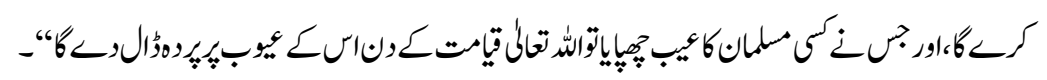

وحدتامتكاتثظ:

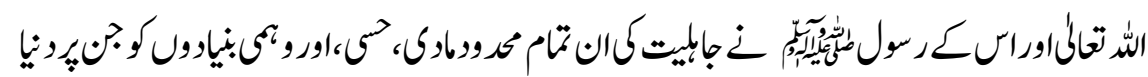

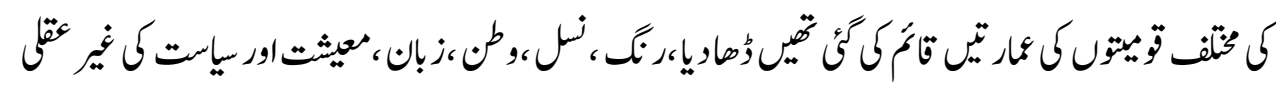

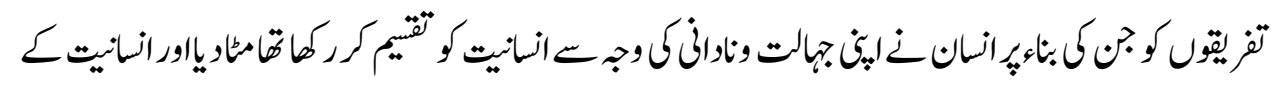

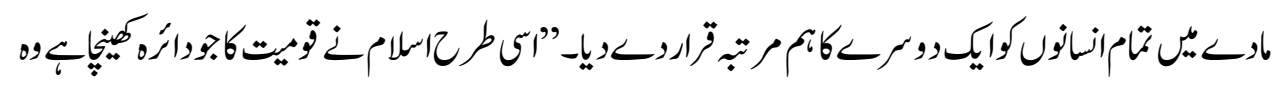

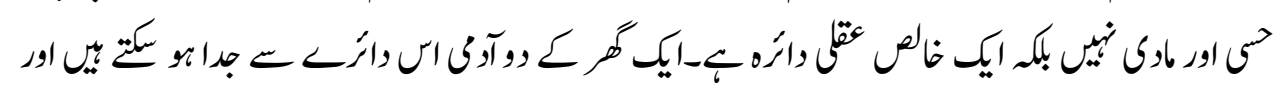

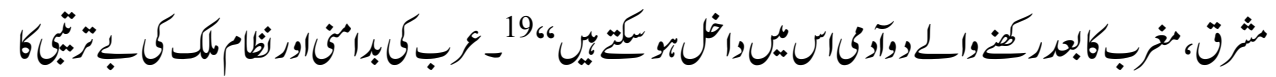

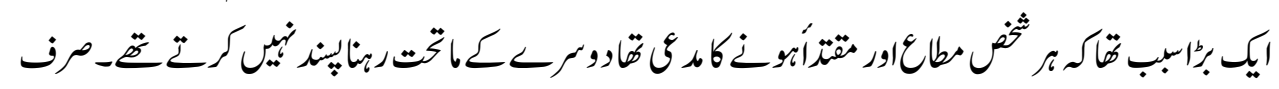

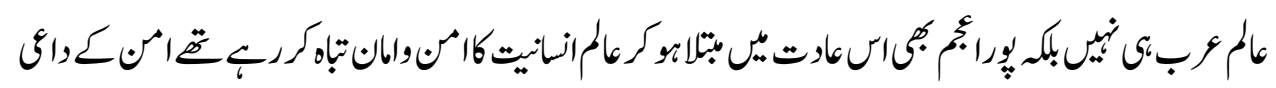




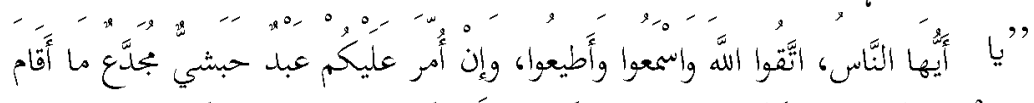

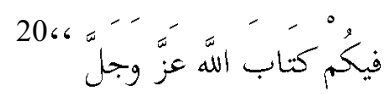

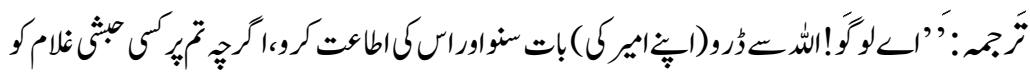

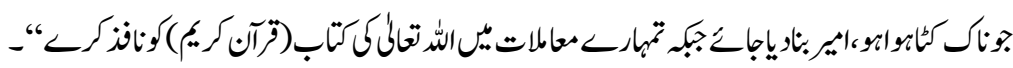

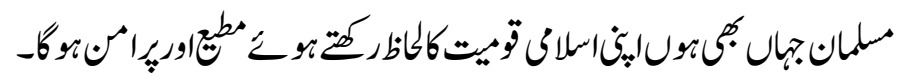

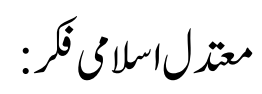

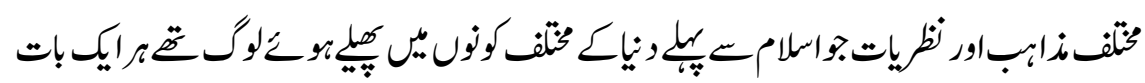

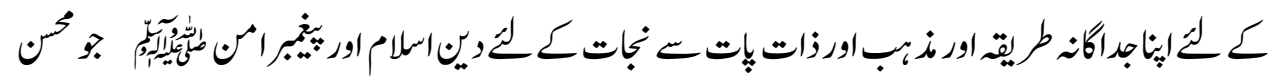

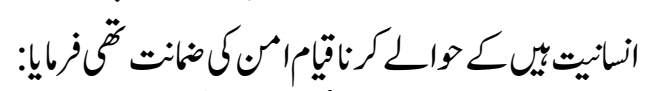

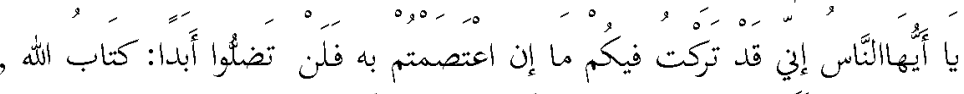

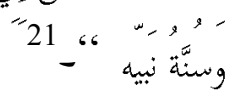

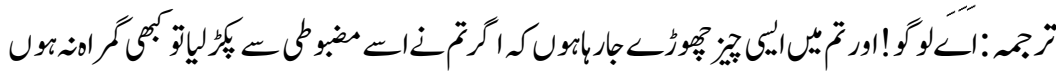

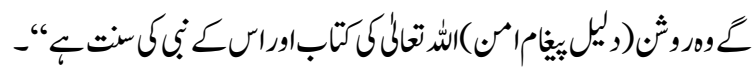

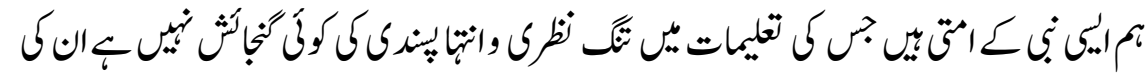

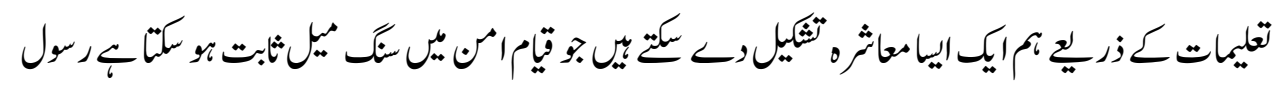

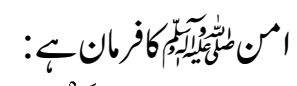

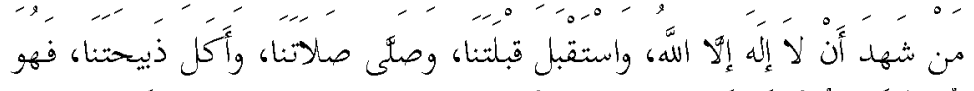

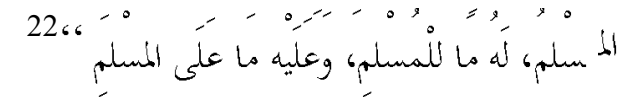

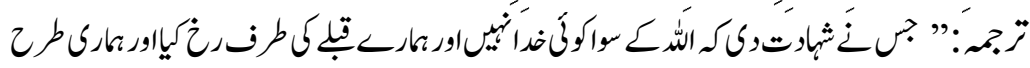

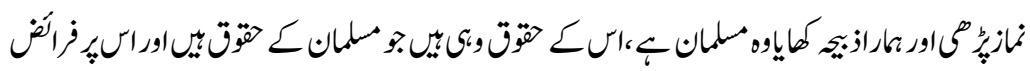

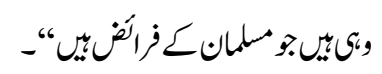

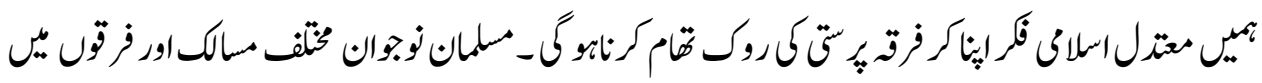

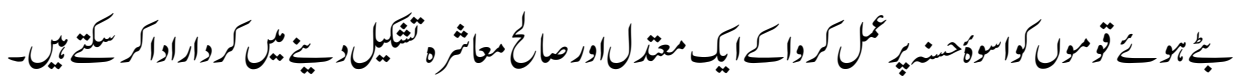




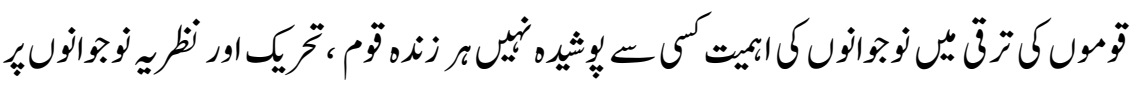

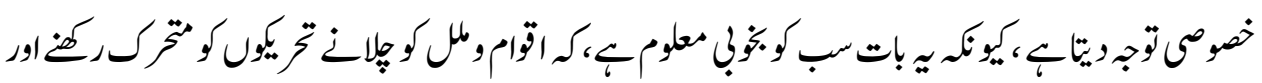

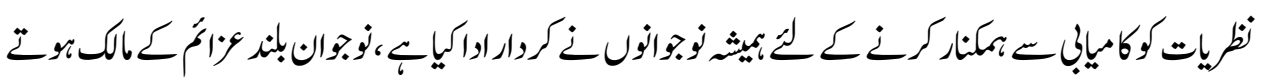

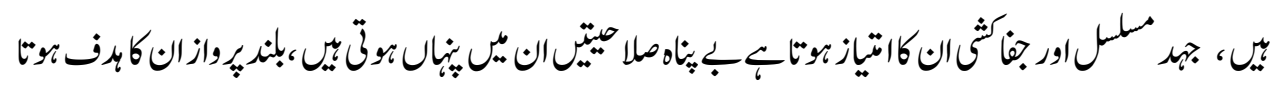

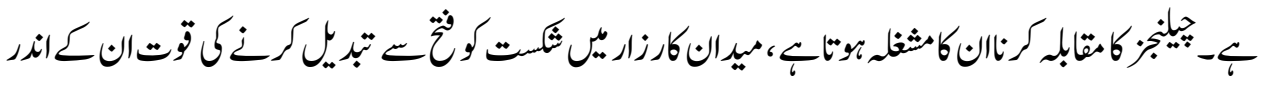

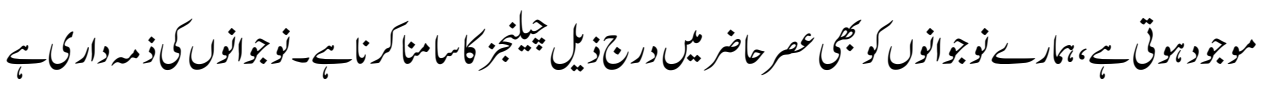

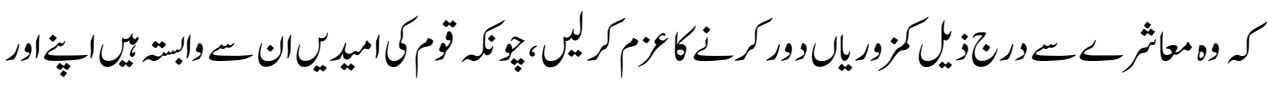

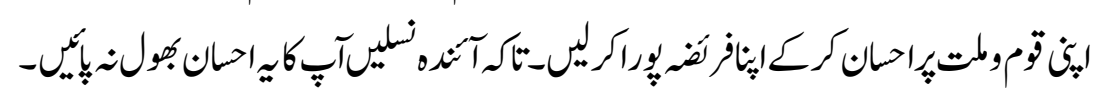

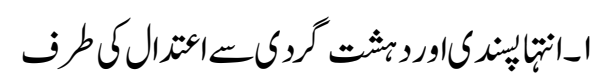

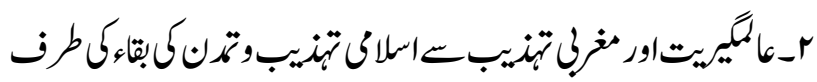

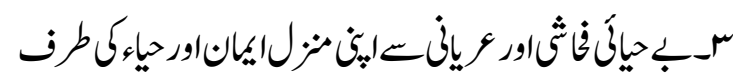

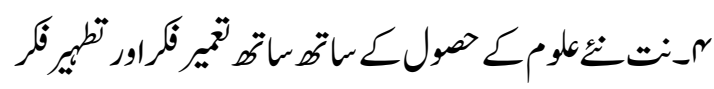

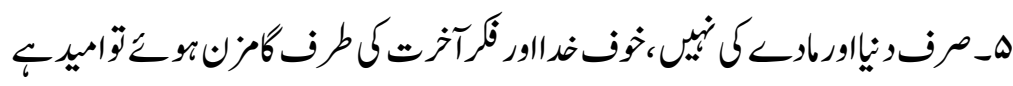

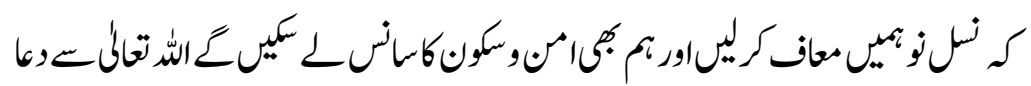

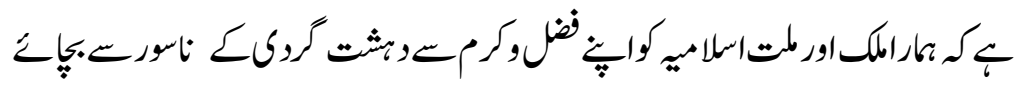

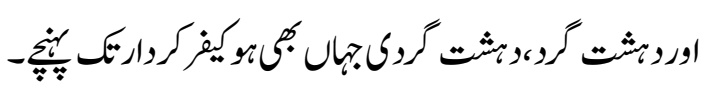

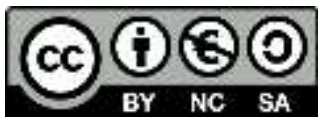

This work is licensed under a Creative Commons Attribution-NonCommercial-ShareAlike 4.0 International (CC BY-NC-SA 4.0) 


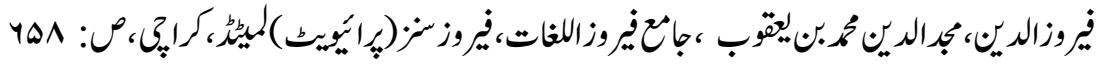

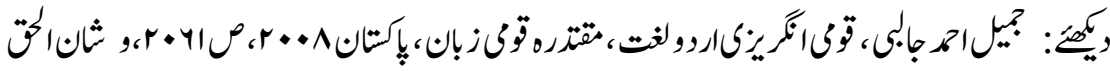

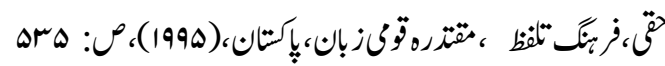

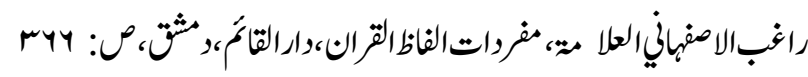

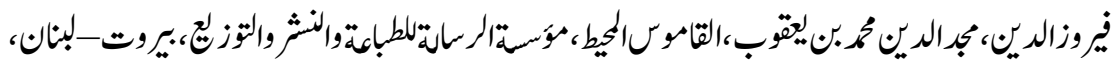

$$
\text { N } 1<: 0
$$

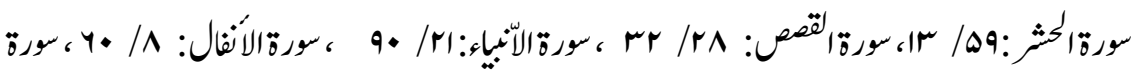

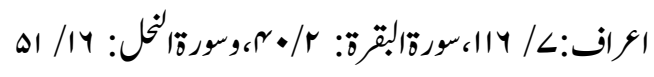

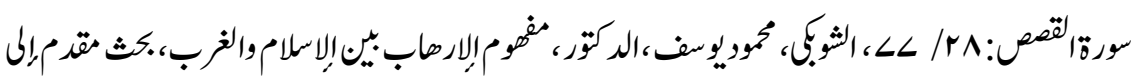

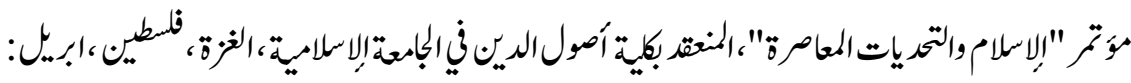

873:2007 م، 2007

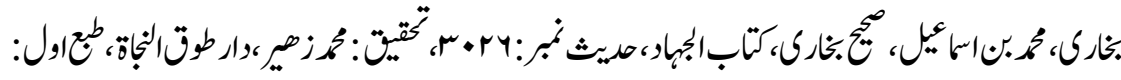

63/4.olere

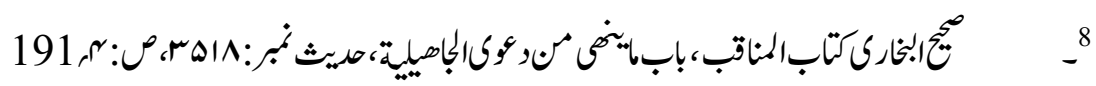

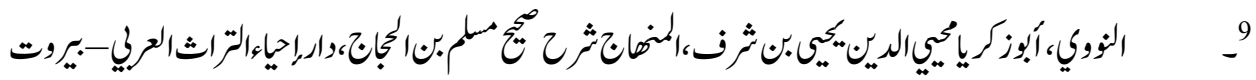

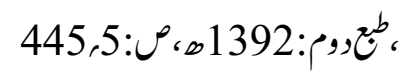

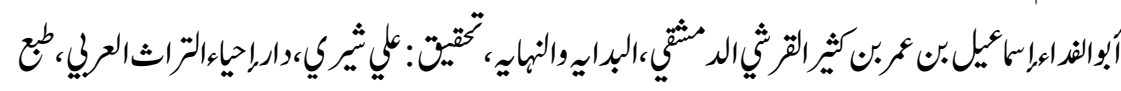

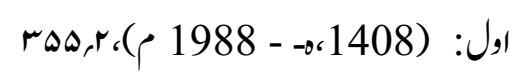

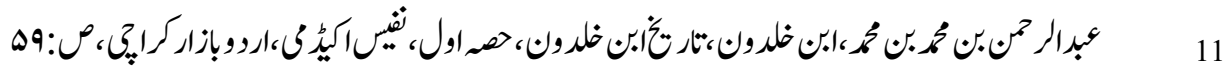

12

$$
13
$$

14

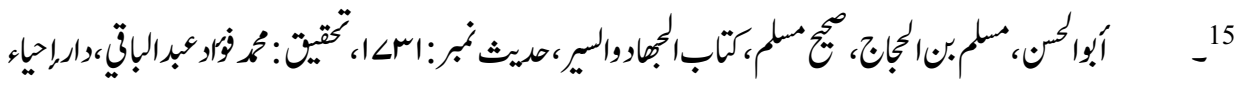

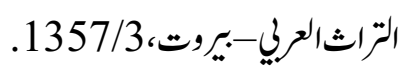




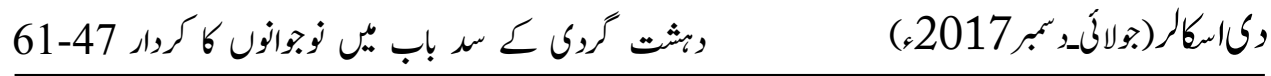

16

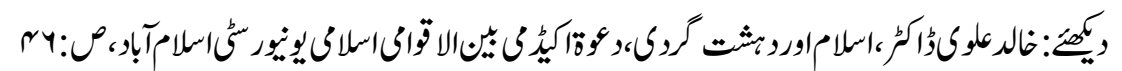

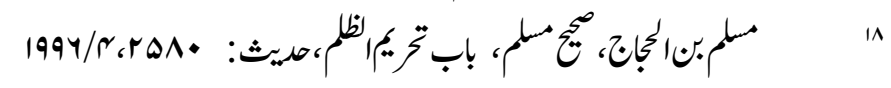
19

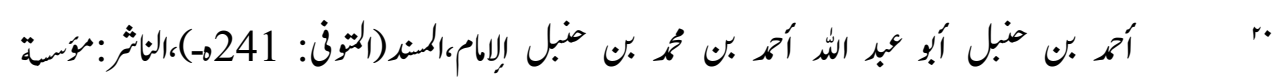

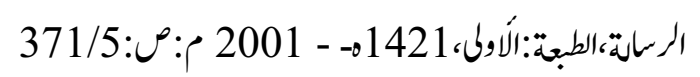

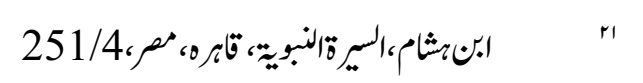

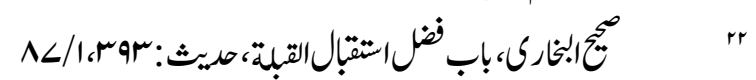

